\title{
Altered Nurr1 protein expression in the hippocampal CA1 region following transient global cerebral ischemia
}

\author{
JOON HA PARK ${ }^{1 *}$, JI HYEON AHN ${ }^{2 *}$, DAE WON KIM ${ }^{3}$, TAE-KYEONG LEE ${ }^{4}$, \\ CHEOL WOO PARK ${ }^{4}$, YOUNG EUN PARK ${ }^{4}$, JAE-CHUL LEE $^{4}$, HYANG-AH LEE $^{5}$, GO EUN YANG $^{6}$, \\ MOO-HO WON ${ }^{4}$ and CHOONG-HYUN LEE ${ }^{7}$
}

\begin{abstract}
${ }^{1}$ Department of Anatomy, College of Korean Medicine, Dongguk University, Gyeongju, Gyeongbuk 38066;
${ }^{2}$ Department of Biomedical Science, Research Institute of Bioscience and Biotechnology, Hallym University, Chuncheon, Gangwon 24252; ${ }^{3}$ Department of Biochemistry and Molecular Biology, and Research Institute of Oral Sciences, College of Dentistry, Gangneung-Wonju National University, Gangneung, Gangwon 25457; Departments of ${ }^{4}$ Neurobiology, and ${ }^{5}$ Obstetrics and Gynecology, School of Medicine, Kangwon National University, Chuncheon, Gangwon 24341;

${ }^{6}$ Department of Radiology, Kangwon National University Hospital, Chuncheon, Gangwon 24289; ${ }^{7}$ Department of Pharmacy, College of Pharmacy, Dankook University, Cheonan, Chungcheongnam-do 31116, Republic of Korea
\end{abstract}

Received May 22, 2019; Accepted September 10, 2019

DOI: $10.3892 / \mathrm{mmr} .2019 .10828$

\begin{abstract}
Nuclear receptor related 1 protein (Nurr1), a member of the nuclear receptor 4 family of orphan nuclear receptors, has been reported to display anti-inflammatory properties. The present study investigated the alteration of Nurr1 immunoreactivity in the gerbil hippocampus proper following $5 \mathrm{~min}$ of transient global cerebral ischemia. In sham operated gerbils, Nurr1 immunoreactivity was observed in pyramidal neurons in all cornu ammonis 1-3 (CA1-3) subfields of the hippocampus proper. In ischemia-operated gerbils, Nurr1 immunoreactivity was altered in the CA1 subfield. Nurr1 immunoreactivity in CA1 pyramidal neurons gradually decreased until 2 days post-ischemia, and, at 4 days post-ischemia, Nurr1 immunoreactivity was concentrated in CA1 pyramidal neurons. Additionally, Nurr1 immunoreactivity was newly expressed in microglia in the CA1 subfield at 4 days post-ischemia. Conversely, in the CA2/3 subfield, time-dependent alteration of Nurrl immunoreactivity was not identified at any time following ischemia. These results indicated that the alteration
\end{abstract}

Correspondence to: Professor Moo-Ho Won, Department of Neurobiology, School of Medicine, Kangwon National University, 1 Gangwondaehak, Chuncheon, Gangwon 24341, Republic of Korea E-mail: mhwon@kangwon.ac.kr

Professor Choong-Hyun Lee, Department of Pharmacy, College of Pharmacy, Dankook University, 119 Dandae-ro, Cheonan, Chungcheongnam-do 31116, Republic of Korea

E-mail: anaphy@dankook.ac.kr

*Contributed equally

Key words: nuclear receptor related 1 protein, transient global cerebral ischemia, delayed neuronal death, CA1-3 subfields, microglia of Nurrl expression in the CA1 subfield in the hippocampus may be associated with the death of CA1 pyramidal neurons.

\section{Introduction}

The hippocampus, a part of the limbic system, has been known to be one of the most vulnerable regions in the brain following transient global cerebral ischemia (tgCI) (1). Especially, tgCI leads to selective neuronal death at a few days, which is called 'delayed neuronal death, after a brief tgCI in the CA1 subfield among the four subfields (CA1-CA4) of the hippocampus proper, while the CA3 subfield is known as the most tolerant hippocampal subregion against tgCI $(2,3)$. Until now, many studies have made an effort to explain the pathophysiology of tgCI-induced neuronal death/damage in the CA1 subfield (4-6); however, the precise underlying mechanisms of tgCI-induced selective and delayed neuronal death in the CA1 subfield have not been fully understood.

Nuclear receptor related 1 protein (Nurr1), also known as $\mathrm{NR} 4 \mathrm{~A} 2$, is a member of nuclear receptor 4 family of orphan nuclear receptors, and Nurrl has been studied to be expressed in various types of neurons and glia in the central nervous system (7-11). The Nurrl function has been known as a transcriptional activator of endogenous tyrosine hydroxylase in neural progenitor cells and participates in the development and maintenance of dopaminergic neurons in the mesencephalon (12-15). In the hippocampus, Nurr1 is expressed in pyramidal neurons in the stratum pyramidale of the hippocampus proper (CA1-CA3 subfields) (16).

Recent studies have suggested that Nurrl in the hippocampus proper plays a major role in cognitive function and stress $(10,17,18)$. Additionally, it has been demonstrated that Nurr1 can display neuroprotective and anti-inflammatory properties (9,19-22). Also, some studies have reported that Nurr1 expression is altered in rodent brains following cerebral ischemia (23-27). However, the expressional changes of 
Nurrl in the hippocampus proper after tgCI have not been fully elucidated. In the present study, thus, we investigated the time-dependent changes of Nurrl expression in the hippocampus proper after $5 \mathrm{~min}$ of $\operatorname{tgCI}$ in gerbils, which are an excellent animal model of $\operatorname{tg} \mathrm{CI}(5,28)$.

\section{Materials and methods}

Experimental animals. Six-month old male Mongolian gerbils (body weight, 70-80 g) were obtained from the Experimental Animal Center, Kangwon National University, Chuncheon, Republic of Korea. Animal care and all experimental procedures were approved by Institutional Animal Care and Use Committee at Kangwon National University (approval no. KW-180124-1). We minimized numbers of the gerbils used in this study and the suffering caused by the procedures used in this experiment.

Induction of $\operatorname{tg} C I$. As described in our published papers (29-32), the surgical procedure for tgCI was as follows. Briefly, gerbils (total $n=103$; 63 gerbils for histological analysis and 40 gerbils for western blot analysis) were anesthetized with a mixture of $2.5 \%$ isoflurane in $34 \%$ oxygen $\left(\mathrm{O}_{2}\right)$ and $66 \%$ nitrous oxide $\left(\mathrm{N}_{2} \mathrm{O}\right)$. Blood flow to the brain was completely interrupted by bilateral common carotid artery occlusion (BCCAO) for $5 \mathrm{~min}$ by using aneurysm clips in order to confirm stop of blood flow in the central artery in retinae under an ophthalmoscope. Body temperature was controlled under normothermic $\left(37 \pm 0.5^{\circ} \mathrm{C}\right)$ condition with a rectal temperature probe: Normothermia was controlled with a thermometric blanket before and during the surgery. Sham operated gerbils were subjected to the same procedure without BCCAO.

Preparation of histological sections. Brain sections containing the hippocampus were prepared from sham and ischemia operated gerbils ( $\mathrm{n}=7$ at each point in time) at designated times $(6,12 \mathrm{~h}, 1,2,3,4,7$ and 10 days after $\operatorname{tgCI})$. Brain sections from the sham operated gerbils $(n=7)$ were prepared at 4 days after tgCI. As described in our published papers (29-32), the gerbils were intraperitoneally anaesthetized with sodium pentobarbital $(60 \mathrm{mg} / \mathrm{kg})$ (JW Pharm. Co., Ltd.) and perfused transcardially with $0.1 \mathrm{M}$ phosphate-buffered saline (PBS) followed by $4 \%$ paraformaldehyde. The brains were removed, postfixed with the same fixative for $8 \mathrm{~h}$ and cryoprotected by soaking in a 30\% sucrose solution for $12 \mathrm{~h}$. The brain tissues were serially sectioned into $30-\mu \mathrm{m}$ thickness of coronal sections in a cryostat (Leica).

Examination of delayed neuronal death. To examine tgCI-induced delayed neuronal death in the hippocampus proper, CV staining and Fluoro-Jade B (FJB) histofluorescence staining were performed by methods as we described previously $(29,30)$. In brief, the sections were stained with solution of CV acetate (Sigma), which was dissolved at $1.0 \%$ (w/v) and contained $0.28 \%$ glacial acetic acid, for $2 \mathrm{~min}$. And the stained sections were washed and dehydrated in ethanol series. For FJB histofluorescence, the sections were serially stained with a $1 \%$ sodium hydroxide solution, a $0.06 \%$ potassium permanganate solution and a $0.0004 \%$ FJB (Histochem) solution. The reacted sections were examined using an epifluorescent microscope (Carl Zeiss) equipped with a blue excitation light $(450-490 \mathrm{~nm})$ and a barrier filter.

Immunohistochemistry. As we described in our published papers (29-32), immunohistochemical staining for Nurrl was performed as follows. In brief, the brain sections were incubated with mouse anti-Nurr1 (1:100, Thermo Fisher Scientific, Inc.) as primary antibody and exposed to biotinylated goat anti-mouse IgG and streptavidin peroxidase complex (Vector) as secondary antibody. Finally, the reacted sections were visualized with 3,3'-diaminobenzidine (in $0.1 \mathrm{M}$ Tris- $\mathrm{HCl}$ buffer, $\mathrm{pH}$ 7.4).

In order to establish the specificity of Nurr1 immunoreaction, negative control test was done by using pre-immune serum instead of the primary antibody. The negative control showed no immunoreactivity in the immunostained tissues.

For the quantitative analysis of Nurrl immunoreactivity, 6 sections were selected with $120-\mu \mathrm{m}$ interval per animal, and digital images of Nurrl immunoreactivity were captured with Axio Imager 2 microscope (Carl Zeiss) equipped with a digital camera (Axiocam; Carl Zeiss). According to our published method (31), the images were calibrated into an array of $512 \times 512$ pixels corresponding to a tissue area of $140 \times 140 \mu \mathrm{m}$ including the stratum pyramidale of the sham and ischemia operated gerbils. The density of all Nurrl-immunoreactive structures was evaluated as relative optical density (ROD) as follows. Optical density (RO) of all the Nurrl-immunoreactive structures were obtained after the transformation of the mean gray level using the formula: $O D=\log (256 /$ mean gray level), and the OD of background was taken from the areas adjacent to the measured area. Finally, a ratio of the OD was calibrated as \% (ROD) by using NIH Image 1.59 software.

Double immunofluorescence staining. To examine the cell type containing Nurrl immunoreactivity, double immunofluorescence staining was performed after tgCI according to our published protocol $(30,31)$. In brief, we used mouse anti-Nurr1 (1:40, Thermo Fisher Scientific, Inc.)/rabbit anti-NeuN (a marker for neurons; 1:800, Millipore), rabbit anti-ionized calcium-binding adapter molecule 1 (Iba-1, a marker for microglia; 1:100, Wako) or rabbit anti-glial fibrillary acidic protein (GFAP, a marker for astrocytes; 1:200, Millipore). The sections were incubated in the mixture of antisera and reacted in a mixture of $\mathrm{Cy} 3$-conjugated goat anti-mouse IgG (1:200; Jackson ImmunoResearch, West Grove, PA, USA) and FITC-conjugated goat anti-rabbit IgG (1:200; Jackson ImmunoResearch). The immunoreactions were observed under a confocal MS (LSM510 META NLO, Carl Zeiss).

Western blot analysis. Nurrl protein level in the CA1 subfield were analyzed at designated times $(6,12 \mathrm{~h}, 1,2,4,7$ and 10 days after tgCI) using western blot method according to our published procedure $(29,30)$. In brief, 5 animals at each point in time were intraperitoneally anaesthetized with sodium pentobarbital $(60 \mathrm{mg} / \mathrm{kg})$, and their brains were removed. The brains were serially and transversely cut into $400-\mu \mathrm{m}$ thickness using a vibratome (Leica). Hippocampal CA1 fields were cut by using a surgical blade and homogenized in $50 \mathrm{mM}$ PBS (pH 7.4) containing $0.1 \mathrm{mM}$ ethylene glycol bis (2-aminoethyl 

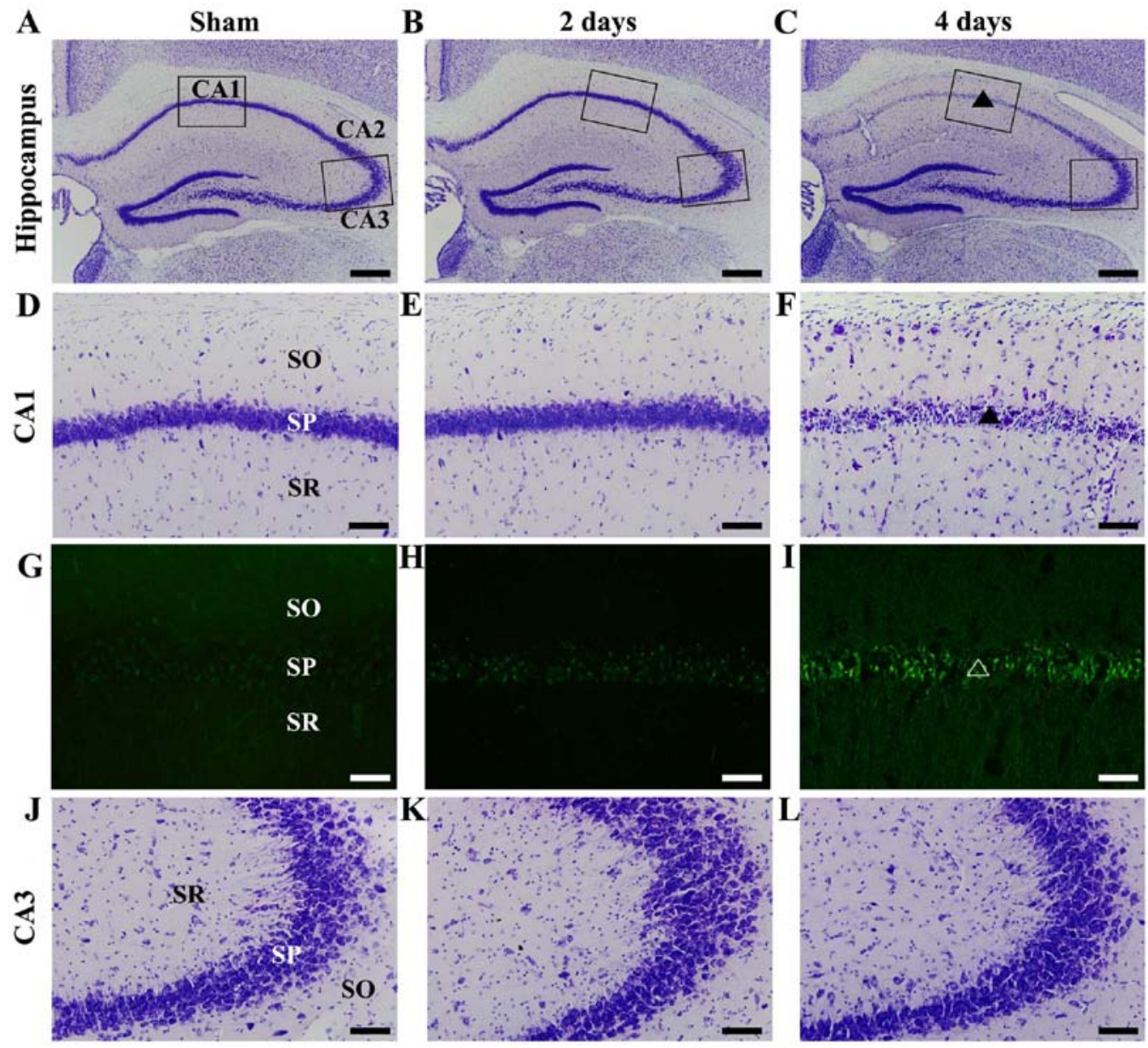

Figure 1. CV and FJB histofluorescence staining in the gerbil hippocampus. (A-C) Low magnification image of CV staining in the gerbil hippocampus of the (A) sham and (B and C) ischemia groups. The squares in the CA1 and CA3 areas indicate the positions of the high magnification images in (D-F and J-L). (D-F) High magnification images of CV staining in the CA1 subfield of the (D) sham and (E and F) ischemia groups. CV-positive cells disappear (triangle) in the SP of the CA1 subfield at 4 days after tgCI. (G-I) High magnification images of FJB histofluorescence staining in the CA1 subfield of the (G) sham and (H and I) ischemia groups. Numerous FJB-positive cells were detected (triangle) in the SP of the CA1 subfield at 4 days after tgCI. (J-L) High magnification images of CV staining in the CA3 subfield of the $(\mathrm{J})$ sham and (K and $\mathrm{L}$ ) ischemia groups. CV-positive cells were intact in the CA3 subfield until 4 days after tgCI. SO, stratum oriens; SR, stratum radiatum. Scale bar, $400 \mu \mathrm{m}$ (A-C) or $50 \mu \mathrm{m}$ (D-L). CV, Cresyle violet; FJB, Fluoro-Jade B; tgCI, transient global cerebral ischemia; SO, stratum oriens; SR, stratum radiatum; SP, stratum pyramidale; CA, cornu ammonis.

ether)-N,N,N0,N0 tetraacetic acid (pH 8.0), 0.2\% Nonidet $\mathrm{P}-40,10 \mathrm{mM}$ ethylendiamine tetraacetic acid ( $\mathrm{pH} 8.0)$, $15 \mathrm{mM}$ sodium pyrophosphate, $100 \mathrm{mM} \beta$-glycerophosphate, $50 \mathrm{mM} \mathrm{NaF}, 150 \mathrm{mM} \mathrm{NaCl}, 2 \mathrm{mM}$ sodium orthovanadate, $1 \mathrm{mM}$ phenylmethylsulfonyl fluoride and $1 \mathrm{mM}$ dithiothreitol (DTT). The homogenized tissues were centrifugated at $16,000 \mathrm{x}$ g for $25 \mathrm{~min}$, and protein levels were determined using a Micro BCA protein assay kit (Pierce Chemical). Aliquot containing total protein $(20 \mathrm{mg}$ ) was boiled in loading buffer containing $150 \mathrm{mM}$ Tris-HCI (pH 6.8), 6\% SDS, 3 mM DTT, $0.3 \%$ bromophenol blue and $30 \%$ glycerol and loaded onto $10 \%$ polyacrylamide gel. The gel was transferred to nitrocellulose transfer membranes (Pall Crop.) after electrophoresis. The background of the membrane was reduced with $5 \%$ nonfat dry milk in PBS containing $0.1 \%$ Tween 20 for $40 \mathrm{~min}$, and the membrane was reacted with mouse anti-Nurr1 (1:200; Thermo Fisher Scientific, Inc.), peroxidase-conjugated goat anti-mouse IgG and ECL kit. The loading control was carried out using mouse anti- $\beta$-actin $(1: 5,000)$ antibody. Western blot analysis using homogenates at all experimental time-points was performed simultaneously. Results of the western blotting were scanned, and the quantification of the bands was densitometrically analyzed using NIH Image 1.59 software. The quantification was represented by relative optical density (ROD). A ratio of the ROD was calibrated as \%: The sham operated group was designated as $100 \%$.

Statistical analysis. The data shown here represent the means \pm SEM. Differences of the means among the groups were statistically analyzed by analysis of variance (ANOVA) with Duncan's post hoc test in order to elucidate ischemia-related differences among experimental groups. $\mathrm{P}<0.05$ was considered to indicate a statistically significant difference.

\section{Results}

tgCI-induced delayed neuronal death. tgCI-induced delayed neuronal death in the hippocampus proper (CA1-3 subfields) was examined at 2 days and 4 days after tgCI using CV staining and FJB histofluorescence staining. In the sham group, cells in the CA1-3 subfields were easily stained with CV. In particular, pyramidal neurons of the stratum pyramidale of the CA1-3 

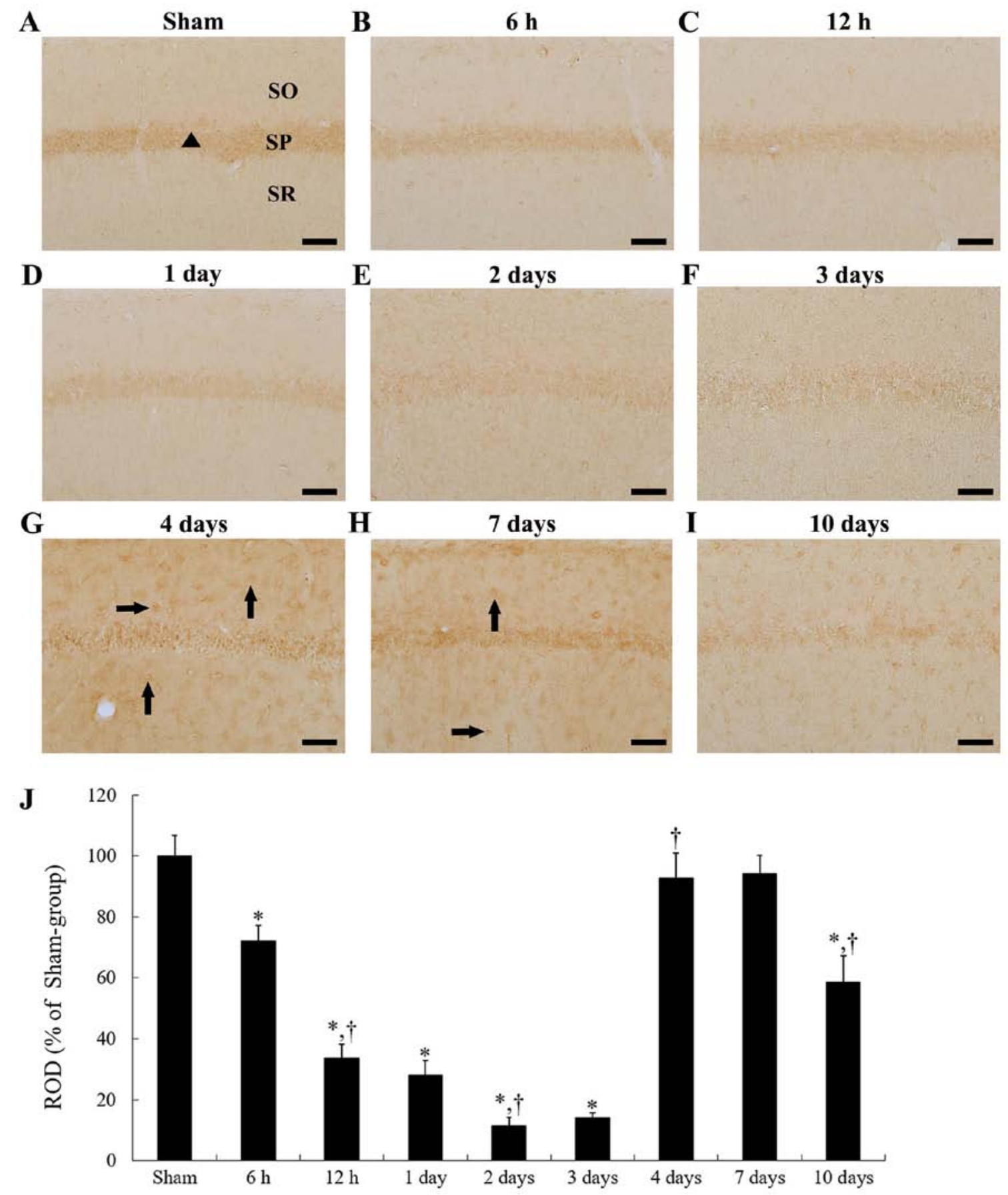

Figure 2. Immunoreactivity of Nurr1 in the CA1 subfield of the (A) sham and (B-I) ischemia groups. Nurr1 immunoreactivity in the sham group was observed in CA1 pyramidal neurons (triangle). In the ischemia group, Nurrl immunoreactivity in CA1 pyramidal neurons gradually decreased until 2 days and 3 days post-ischemia. At 4 days and 7 days post-ischemia, Nurr1 immunoreactivity was increased in non-pyramidal cells (arrows) of the CA1 subfield. Subsequently, Nurrl immunoreactivity in the CA1 subfield was decreased again at 10 days after tgCI. Scale bar, $50 \mu \mathrm{m}$. (J) ROD as \% of Nurrl-immunoreactive structures in the $\mathrm{CA} 1$ subfield after $\operatorname{tgCI}\left(\mathrm{n}=7\right.$ at each time point). Bars indicate the means $\pm \mathrm{SEM}$. ${ }^{*} \mathrm{P}<0.05$ vs. sham group; ${ }^{\circ} \mathrm{P}<0.05$ vs. previous time point. tgCI, transient global cerebral ischemia; SO, stratum oriens; SP, stratum pyramidale; SR, stratum radiatum; CA, cornu ammonis; Nurr1, nuclear receptor related 1 protein.

subfields were large and pyramidal in shape (Fig. 1A, D and J). In the ischemia group, no difference in $\mathrm{CV}$ staining in the hippocampus proper was found at 2 days after $\operatorname{tgCI}$, compared to the sham group (Fig. 1B, E and K). On the other hand, most of $\mathrm{CV}$-positive pyramidal neurons in the stratum pyramidale of the CA1 subfield were dead at 4 days after tgCI (Fig. 1C and F). At this point of time, many FJB positive cells were observed in the stratum pyramidale of the CA1 subfield (Fig. 1I). However, $\mathrm{CV}$-positive pyramidal neurons in the $\mathrm{CA} 2 / 3$ subfield were not damaged at 4 days after tgCI (Fig. 1C and L). In addition, any FJB positive cells were not found in the CA2/3 subfield (data not shown). This result is consistent with the results of our previous studies (29-31).

tgCI-induced change of Nurrl immunoreactivity in CAI subfield. In the sham group, Nurr1 immunoreactivity was primarily shown in pyramidal neurons of the stratum pyramidale of the hippocampus proper (CA1-3 subfields) (Fig. 2A). 


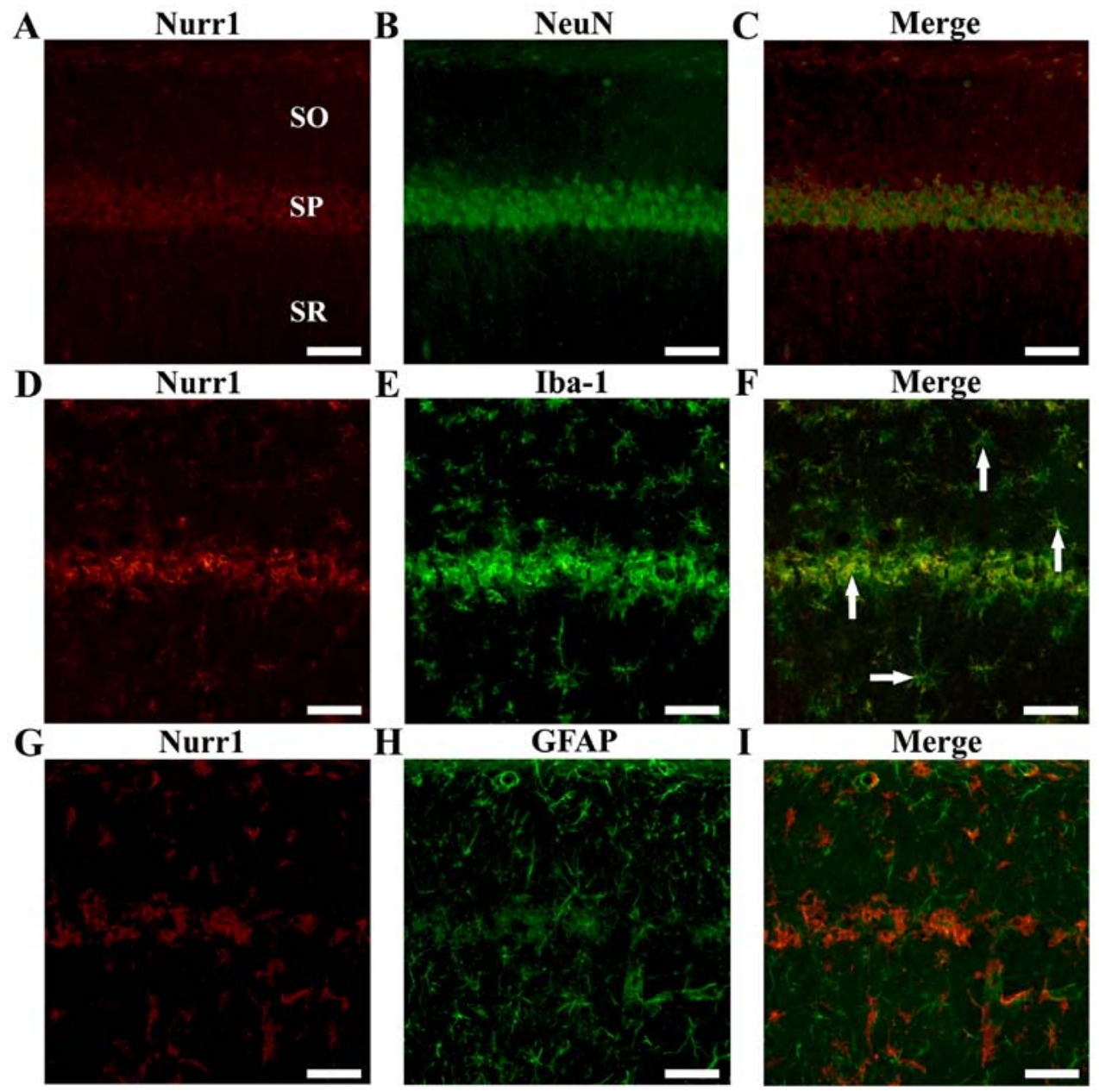

Figure 3. Double immunofluorescence staining for (A, D and G) Nurr1 (red), (B) NeuN (green) for neurons, (E) Iba-1 (green) for microglia or (H) GFAP (green) for astrocytes, and (C, F and I) merged images in the CA1 subfield. Nurrl-immunoreactive cells were colocalized with NeuN-immunoreactive neurons in the sham operated group. At 4 days after tgCI, Nurrl-immunoreactive cells expressed Iba-1 immunoreactivity (arrows) in the CA1 subfield of the ischemia operated group. Scale bar, $50 \mu \mathrm{m}$. tgCI, transient global cerebral ischemia; SO, stratum oriens; SP, stratum pyramidale; SR, stratum radiatum; CA, cornu ammonis; Nurr1, nuclear receptor related 1 protein; NeuN, neuronal nuclei; Iba-1, allograft inflammatory factor 1.

In the CA1 subfield of the ischemia group, Nurr1 immunoreactivity in the CA1 pyramidal neurons began to decrease from $6 \mathrm{~h}$ after $\operatorname{tgCI}$, and the immunoreactivity was gradually decreased with a time-dependent manner until 3 days after $\operatorname{tgCI}$ (Fig. 2B-F and J). Especially, at 2 and 3 days after tgCI, Nurr1 immunoreactivity in the CA1 pyramidal neurons was hardly detected (Fig. 2E and F). However, Nurr1 immunoreactivity was increased in the CA1 subfield at 4 and 7 days after $\operatorname{tgCI}$ (Fig. 2G, H and J). At these points of time, Nurrl-immunoreactive cells were observed in the stratum pyramidale of the CA1 subfield, and Nurr1 immunoreactivity was detected in non-pyramidal cells of the stratum oriens and radiatum in the CA1 subfield (Fig. 2G and $\mathrm{H}$ ). And then, Nurrl immunoreactivity was decreased in the CA1 subfield at 10 days after tgCI (Fig. 2I and J).

Nurrl expression in neurons or microglia. As shown in Fig. 2A, Nurrl immunoreactivity was observed in the stratum pyramidale of the CA1 subfield of the sham operated group. To confirm whetherNurrl is expressed in pyramidal neurons, double immunofluorescence staining was performed for Nurrl/NeuN (neurons). We found that Nurr1-immunoreactive cells were colocalized with NeuN-immunoreactive neurons in the CA1 subfield of the sham operated group (Fig. 3A-C).

In addition, as shown in Fig. $2 \mathrm{~F}$ and $\mathrm{G}$, Nurrl immunoreactivity was newly expressed in non-pyramidal cells in the CA1 subfield at 4 days after tgCI. To identify the cell type, double immunofluorescence staining was performed for Nurr1/Iba-1 (microglia) and Nurr1/GFAP (astrocytes). We found that Nurr1-immunoreactive cells were colocalized with Iba-1-immunoreactive microglia, not with GFAP-immunoreactive astrocytes, in the CA1 subfield at 4 days after $\operatorname{tgCI}$ (Fig. 3D-I).

tgCI-induced change of Nurrl immunoreactivity in CA2/3 subfield. Unlike the tgCI-induced change of Nurrl immunoreactivity in the CA1 subfield, Nurrl immunoreactivity in the CA2/3 subfield was not significantly changed at any times after $\operatorname{tgCI}$ (Fig. 4A-D).

tgCI-induced change of Nurrl protein level. Nurrl protein level in the CA1 field was significantly changed with time after tgCI (Fig. 5), showing that the pattern of change of Nurrl protein level was similar to that observed in the immunohistochemical 
A

Sham

B

2 days

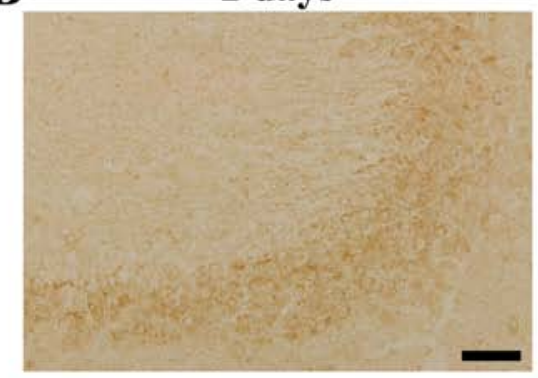

C

4 days
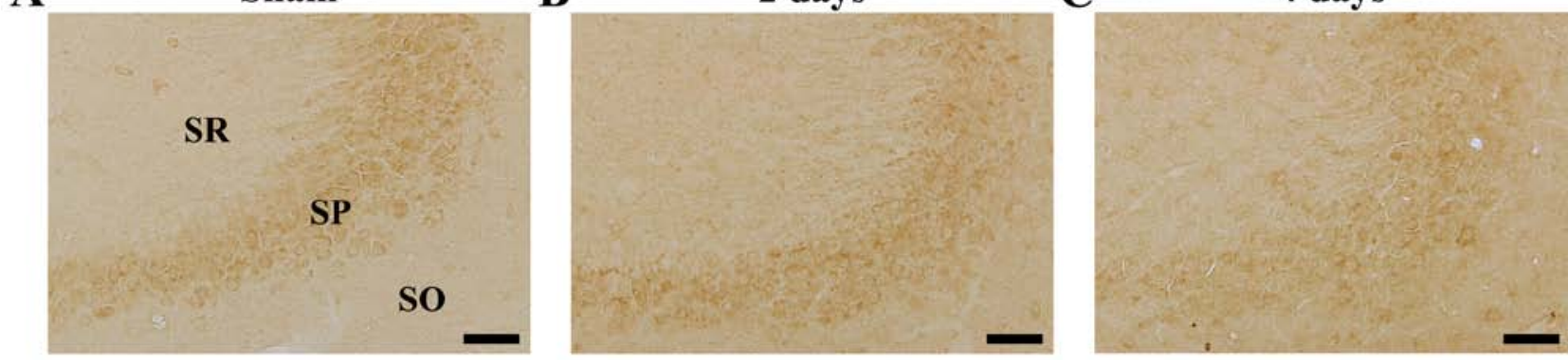

D

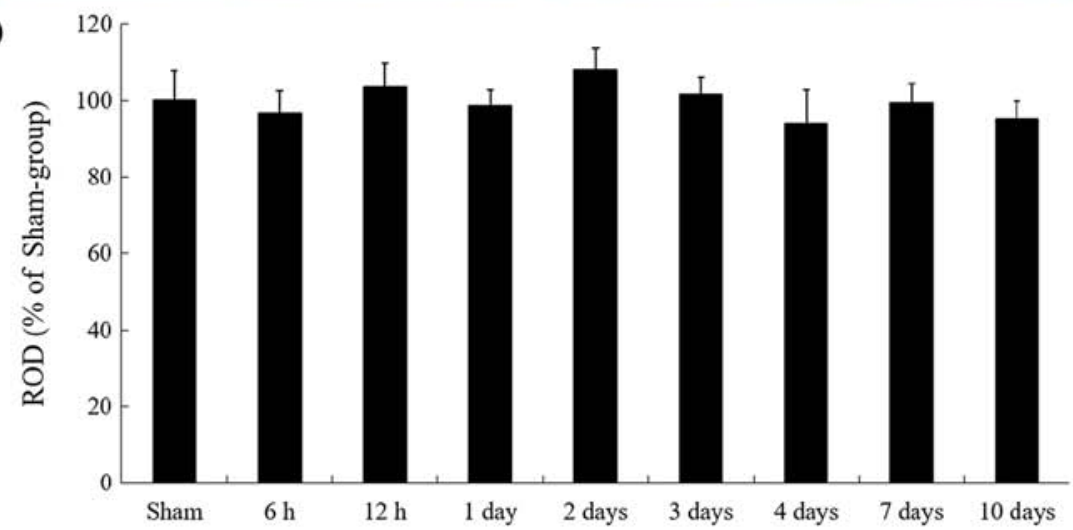

Figure 4. Immunoreactivity of Nurr1 in the CA3 subfield of the (A) sham and (B and C) ischemia groups. Nurrl immunoreactivity in CA3 pyramidal neurons was not altered at (B) 2 and (C) 4 days following tgCI. Scale bar, $50 \mu \mathrm{m}$. (D) ROD as \% of Nurrl-immunoreactive structures in the CA3 subfield after tgCl ( $\mathrm{n}=7$ at each time point). Bars indicate the means \pm SEM. SO, stratum oriens; SP, stratum pyramidale; SR, stratum radiatum; Nurrl, nuclear receptor related 1 protein; $\mathrm{CA}$, cornu ammonis; $\operatorname{tg} \mathrm{CI}$, transient global cerebral ischemia.

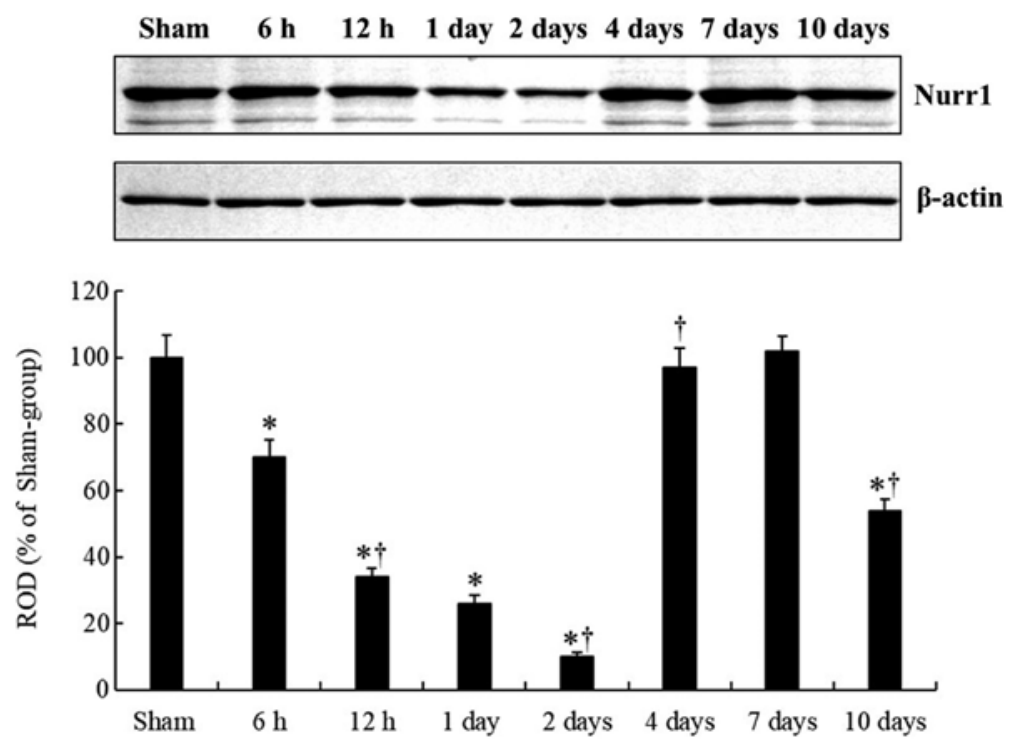

Figure 5. Western blot analysis of Nurrl in the cornu ammonis 1 subfield of the sham-operated and ischemia-operated gerbils. ROD as \% value of immunoblot band is represented ( $\mathrm{n}=5$ at each time point). ${ }^{*} \mathrm{P}<0.05$ vs. sham group; ${ }^{\dagger} \mathrm{P}<0.05$ vs. previous time point. Bars indicate the means $\pm \mathrm{SEM}$. Nurrl, nuclear receptor related 1 protein.

data. Nurr1 protein level was significantly decreased at $6 \mathrm{~h}$ after tgCI compared to that of the sham operated group, and it was gradually decreased until 2 days after tgCI. At 4 days after tgCI, Nurr1 protein level was significantly increased, compared to that at 2 days after tgCI. At 7 days after tgCI, Nurrl protein level was not different from that at 4 days after $\operatorname{tgCI}$. And then, Nurrl protein level was significantly decreased at 10 days after $\operatorname{tgCI}$, compared to that at 7 days after tgCI.

\section{Discussion}

In this study, we examined neuronal death in the CA1 subfield after $\operatorname{tgCI}$ and found that CA1 pyramidal neurons did not die until 2 days after tgCI; however, CA1 pyramidal neurons died at 4 days post-tgCI. On the other hand, pyramidal neurons in the CA3 subfield did not die at any time after tgCI. These findings are consistent with results of previous studies $(30,32)$. 
Some previous studies have reported that brain ischemic insults cause changes of Nurrl expression in various rodent models of cerebral ischemia $(23,25,27)$. However, it is unclear if Nurr1 has a neuroprotective or detrimental effect against cerebral ischemia injury. It has been reported that a level of Nurr1 mRNA increased in the cerebral cortex following permanent middle cerebral artery occlusion (MCAO) in rats (25). They have also shown that Nurr1 mRNA is induced in pyramidal neurons of the rat hippocampal CA1 and CA 3 subfields at $1 \mathrm{~h}$ after ischemic insult induced by MCAO (25). Recently, Zhang and Yu (27) have reported that protein expression and mRNA transcription of Nurr1 are significantly enhanced in the mouse brain following transient focal ischemia by MCAO, showing that the infarct volume is significantly reduced in Nurrl knockout mice, compared with wild-type mice, after transient focal ischemia. They have urged that an increase of Nurrl is associated with the progression of cerebral ischemia-reperfusion injury and that upregulated Nurr1 is involved in neuronal apoptosis and mitochondrial injury (27). Conversely, other previous studies have reported that cerebral ischemic insults decrease Nurr1 expression in brains $(23,24,26)$. Erdo et al (23) have demonstrated that Nurrl protein expression is down-regulated in the ipsilateral basal ganglia after transient focal ischemia induced by MCAO in mice. Additionally, it has been reported that Nurr1 mRNA expression is not changed in the pyramidal cell layer in the CA1 subfield of the gerbil hippocampus until $24 \mathrm{~h}$ after $5 \mathrm{~min}$ of $\operatorname{tgCI}$, and then decreased at $72 \mathrm{~h}$ after $\operatorname{tgCI}(24)$. Recently, Xie et al (26) have reported that mRNA and protein levels of Nurrl begin to decrease immediately after ischemic damage, reaching a minimum at $12 \mathrm{~h}$ and increase at $48 \mathrm{~h}$ in the rat brain including the hippocampus following transient MCAO. They have also shown that increased expression of Nurrl can inhibit TNF- $\alpha$ expression in microglia, reduce ischemia-induced neuroinflammatory and cytotoxic response in neurons, and decrease infarct volume at an early stage after transient MCAO (26). In this study, we found that Nurrl immunoreactivity, which was shown in pyramidal neurons of the CA1 subfield, gradually decreased with a time-dependent manner after $\operatorname{tgCI}$, and that Nurr1 immunoreactivity in the CA1 pyramidal neurons was markedly weak at 2 and 3 days after tgCI. In addition, Nurrl protein expression in the CA1 subfield was gradually decreased until 2 days after tgCI. However, we found that tgCI-induced change of Nurr1 immunoreactivity in the CA3 subfield was not shown at any time after tgCI. It has been reported that CA3 subfield is known to be a tolerant subfield following $\operatorname{tgCI}(3,29)$. Thus, it can be postulated that tgCI-induced reduction of Nurr1 expression in pyramidal neurons of the CA1 subfield may be closely involved with a process of the tgCI-induced death of CA1 pyramidal neurons.

In the present study, we first found that Nurrl immunoreactivity was detected in non-pyramidal cells in the strata oriens and radiatum of the CA1 subfield at 4 days after tgCI. We examined the type of these non-pyramidal cells and found that they were microglia. It has been reported that Nurr1 expression in microglia is regulated in response to inflammation (33). Additionally, it has well been known that Nurrl can attenuate expressions of proinflammatory and neurotoxic mediators in microglia through its ability to decrease NFאB activation $(8,9,20)$. Additionally, some studies have suggested that beneficial effects of microglia, such as removal of cell debris and production of neurotrophic factors, are effectively played in the ischemic brain regions following ischemic insults $(34,35)$. Thus, it is likely that newly expressed Nurrl in microglia in strata oriens and radiatum of the CA1 subfield may be related with a beneficial effect of microglia following tgCI.

In summary, Nurr1 immunoreactivity was significantly changed in the CA1 subfield, not the CA3 subfield, following tgCI, and Nurrl immunoreactivity was newly expressed in microglia of ischemic CA1 subfield at 4 days after tgCI. These results indicate that tgCI-induced alteration of Nurr1 expression may be closely related with tgCI-induced neuronal death in the hippocampal CA1 subfield.

\section{Acknowledgements}

Not applicable.

\section{Funding}

The present study was carried out with the support of 'Cooperative Research Program for Agriculture Science and Technology Development, Rural Development Administration, Republic of Korea (project no. PJ01321101), and was supported by the Bio \& Medical Technology Development Program of the NRF funded by the Korean government, MSIP (grant no. NRF-2015M3A9B6066835), and by the National Research Foundation of Korea funded by the Ministry of Education (grant no. NRF-2017R1D1A1B03029311).

\section{Availability of data and materials}

All data generated or analyzed during the present study are included in this published article.

\section{Authors' contributions}

TKL, CWP and YEP performed the measurements. DWK, JCL, HAL and GEY analyzed and interpreted data. JHP, JHA, MHW and CHL made substantial contributions to conception and design, and were involved in drafting and revising the manuscript, and interpreting all data. All authors read and approved the final manuscript.

\section{Ethics approval and consent to participate}

The protocol of this experiment was approved by Institutional Animal Care and Use Committee (IACUC) at Kangwon National University (approval no. KW-180124-1). This protocol adhered to guidelines from the current international laws and policies in the 'Guide for the Care and Use of Laboratory Animals'.

\section{Patient consent for publication}

Not applicable.

\section{Competing interests}

The authors declare that they have no competing interests. 


\section{References}

1. Globus MY, Busto R, Martinez E, Valdes I, Dietrich WD and Ginsberg MD: Comparative effect of transient global ischemia on extracellular levels of glutamate, glycine, and gamma-aminobutyric acid in vulnerable and nonvulnerable brain regions in the rat. J Neurochem 57: 470-478, 1991.

2. Kirino T: Delayed neuronal death in the gerbil hippocampus following ischemia. Brain Res 239: 57-69, 1982.

3. Kirino T and Sano K: Selective vulnerability in the gerbil hippocampus following transient ischemia. Acta Neuropathol 62 201-208, 1984

4. Kim H, Ahn JH, Song M, Kim DW, Lee TK, Lee JC, Kim YM, Kim JD, Cho JH, Hwang IK, et al: Pretreated fucoidan confers neuroprotection against transient global cerebral ischemic injury in the gerbil hippocampal CA1 area via reducing of glial cell activation and oxidative stress. Biomed Pharmacother 109: 1718-1727, 2019.

5. Lee JC, Park JH, Kim IH, Cho GS, Ahn JH, Tae HJ, Choi SY, Cho JH, Kim DW, Kwon YG, et al: Neuroprotection of ischemic preconditioning is mediated by thioredoxin 2 in the hippocampal CA1 region following a subsequent transient cerebral ischemia. Brain Pathol 27: 276-291, 2017.

6. Park JH, Kim YH, Ahn JH, Choi SY, Hong S, Kim SK, Kang IJ, Kim YM, Lee TK, Won MH and Lee CH: Atomoxetine protects against NMDA Receptor-mediated hippocampal neuronal death following transient global cerebral ischemia. Curr Neurovasc Res 14: 158-168, 2017.

7. Arimatsu Y, Ishida M, Kaneko T, Ichinose S and Omori A: Organization and development of corticocortical associative neurons expressing the orphan nuclear receptor Nurr1. J Comp Neurol 466: 180-196, 2003.

8. Kim CH, Han BS, Moon J, Kim DJ, Shin J, Rajan S, Nguyen QT, Sohn M, Kim WG, Han M, et al: Nuclear receptor Nurrl agonists enhance its dual functions and improve behavioral deficits in an animal model of Parkinson's disease. Proc Natl Acad Sci USA 112: 8756-8761, 2015.

9. Saijo K, Winner B, Carson CT, Collier JG, Boyer L, Rosenfeld MG, Gage FH and Glass CK: A Nurr1/CoREST pathway in microglia and astrocytes protects dopaminergic neurons from inflammation-induced death. Cell 137: 47-59, 2009.

10. Xiao Q, Castillo SO and Nikodem VM: Distribution of messenger RNAs for the orphan nuclear receptors Nurrl and Nur77 (NGFI-B) in adult rat brain using in situ hybridization. Neuroscience 75: 221-230, 1996.

11. Zou J, Chen Z, Wei X, Chen Z, Fu Y, Yang X, Chen D, Wang R, Jenner $\mathrm{P}, \mathrm{Lu} \mathrm{JH}$, et al: Cystatin $\mathrm{C}$ as a potential therapeutic mediator against Parkinson's disease via VEGF-induced angiogenesis and enhanced neuronal autophagy in neurovascular units. Cell Death Dis 8: e2854, 2017.

12. Chu Y, Kompoliti K, Cochran EJ, Mufson EJ and Kordower JH: Age-related decreases in Nurrl immunoreactivity in the human substantia nigra. J Comp Neurol 450: 203-214, 2002.

13. Decressac M, Volakakis N, Bjorklund A and Perlmann T: NURR1 in Parkinson disease-from pathogenesis to therapeutic potential. Nat Rev Neurol 9: 629-636, 2013.

14. Sakurada K, Ohshima-Sakurada M, Palmer TD and Gage FH: Nurrl, an orphan nuclear receptor, is a transcriptional activator of endogenous tyrosine hydroxylase in neural progenitor cells derived from the adult brain. Development 126: 4017-4026, 1999.

15. Yan W, Chen ZY, Chen JQ and Chen HM: BMP2 promotes the differentiation of neural stem cells into dopaminergic neurons in vitro via miR-145-mediated upregulation of Nurrl expression. Am J Transl Res 8: 3689-3699, 2016.

16. Ahn JH, Lee JS, Cho JH, Park JH, Lee TK, Song M, Kim H, Kang SH, Won MH and Lee $\mathrm{CH}$ : Age-dependent decrease of Nurr1 protein expression in the gerbil hippocampus. Biomed Rep 8: 517-522, 2018.

17. Kim JI, Jeon SG, Kim KA, Kim YJ, Song EJ, Choi J, Ahn KJ, Kim CJ, Chung HY, Moon M and Chung H: The pharmacological stimulation of Nurrl improves cognitive functions via enhancement of adult hippocampal neurogenesis. Stem Cell Res 17: 534-543, 2016.

18. Montes P, Ruiz-Sanchez E, Calvillo M and Rojas P: Active coping of prenatally stressed rats in the forced swimming test: Involvement of the Nurr1 gene. Stress 19: 506-515, 2016.
19. Barneda-Zahonero B, Servitja JM, Badiola N Miñano-Molina AJ, Fadó R, Saura CA and Rodríguez-Alvarez J: Nurr1 protein is required for N-methyl-D-aspartic acid (NMDA) receptor-mediated neuronal survival. J Biol Chem 287: 11351-11362, 2012.

20. De Miranda BR, Popichak KA, Hammond SL, Jorgensen BA, Phillips AT, Safe S and Tjalkens RB: The Nurr1 Activator 1,1-Bis(3'-Indolyl)-1-(p-Chlorophenyl)Methane blocks inflammatory gene expression in BV-2 microglial cells by inhibiting nuclear factor $\kappa$ B. Mol Pharmacol 87: 1021-1034, 2015.

21. Hammond SL, Safe S and Tjalkens RB: A novel synthetic activator of Nurrl induces dopaminergic gene expression and protects against 6-hydroxydopamine neurotoxicity in vitro. Neurosci Lett 607: 83-89, 2015

22. Loppi S, Kolosowska N, Kärkkäinen O, Korhonen $P$, Huuskonen M, Grubman A, Dhungana H, Wojciechowski S, Pomeshchik Y, Giordano M, et al: HX600, a synthetic agonist for RXR-Nurr1 heterodimer complex, prevents ischemia-induced neuronal damage. Brain Behav Immun 73: 670-681, 2018.

23. ErdoF,TrappT,Mies Gand HossmannKA:Immunohistochemical analysis of protein expression after middle cerebral artery occlusion in mice. Acta Neuropathol 107: 127-136, 2004.

24. Honkaniemi J and Sharp FR: Global ischemia induces immediate-early genes encoding zinc finger transcription factors. J Cereb Blood Flow Metab 16: 557-565, 1996.

25. Honkaniemi J, States BA, Weinstein PR, Espinoza J and Sharp FR: Expression of zinc finger immediate early genes in rat brain after permanent middle cerebral artery occlusion. J Cereb Blood Flow Metab 17: 636-646, 1997.

26. Xie X, Peng L, Zhu J, Zhou Y, Li L, Chen Y, Yu S and Zhao Y: miR-145-5p/Nurr1/TNF-a Signaling-induced microglia activation regulates neuron injury of acute cerebral Ischemic/reperfusion in rats. Front Mol Neurosci 10: 383, 2017.

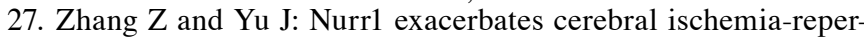
fusion injury via modulating YAP-INF2-mitochondrial fission pathways. Int J Biochem Cell Biol 104: 149-160, 2018.

28. Ginsberg MD and Busto R: Rodent models of cerebral ischemia. Stroke 20: 1627-1642, 1989.

29. Ahn JH, Shin MC, Kim DW, Kim H, Song M, Lee TK, Lee JC, Kim H, Cho JH, Kim YM, et al: Antioxidant properties of fucoidan alleviate acceleration and exacerbation of hippocampal neuronal death following transient global cerebral ischemia in high-fat diet-induced obese gerbils. Int J Mol Sci 20: pii: E554, 2019.

30. Park JH, Noh Y, Kim SS, Ahn JH, Ohk TG, Cho JH, Lee TK, Kim H, Song M, Lee JC, et al: Time-course changes and new expressions of MIP-3a and its receptor, CCR6, in the gerbil hippocampal CA1 area following transient global cerebral ischemia. Neurochem Res 43: 2102-2110, 2018.

31. Park JH, Shin BN, Ahn JH, Cho JH, Kim IH, Kim DW, Won MH, Hong S, Cho JH and Lee $\mathrm{CH}$ : Ischemia-induced changes of PRAS40 and p-PRAS40 immunoreactivities in the gerbil hippocampal CA1 region after transient cerebral ischemia. Cell Mol Neurobiol 36: 821-828, 2016.

32. Park JH, Park CW, Ahn JH, Choi SY, Shin MC, Cho JH, Lee TK, Kim IH, Cho JH, Lee JC, et al: Neuroprotection and reduced gliosis by pre- and post-treatments of hydroquinone in a gerbil model of transient cerebral ischemia. Chem Biol Interact 278: 230-238, 2017.

33. Lallier SW, Graf AE, Waidyarante GR and Rogers LK: Nurrl expression is modified by inflammation in microglia. Neuroreport 27: 1120-1127, 2016.

34. Lu YZ, Lin CH, Cheng FC and Hsueh CM: Molecular mechanisms responsible for microglia-derived protection of Sprague-Dawley rat brain cells during in vitro ischemia. Neurosci Lett 373: $159-164,2005$

35. Stoll G and Jander S: The role of microglia and macrophages in the pathophysiology of the CNS. Prog Neurobiol 58: 233-247, 1999.

This work is licensed under a Creative Commons Attribution-NonCommercial-NoDerivatives 4.0 International (CC BY-NC-ND 4.0) License. 